\title{
Jornalismo e guinada subjetiva
}

\author{
Marcio Serelle
}

\section{Resumo}

A recuperação do "eu" em narrativas jornalísticas contemporâneas, cujo efeito de verdade se dá, entre outros aspectos, pelo testemunho, concebe um modo de relação com os eventos em que o sujeito implicado no relato desvela elementos - seja na distinção do exótico ou na proximidade do olhar autóctone - que frequentemente escapam à percepção objetiva. Este artigo retoma, criticamente, os aspectos condicionantes da objetividade na narrativa jornalística e analisa, à luz da guinada subjetiva, principalmente a obra Gomorra, de Roberto Saviano, sua vinculação entre vida e circunstância. Evocando Pasolini em sua fase corsária, Saviano constrói, em sua denúncia contra a Camorra, reflexão sobre a necessidade de intervenção do intelectual na sociedade em que vive, reivindicando a parcialidade da verdade ao entrecruzar, na reportagem, experiência, afetividade e informação.

Palauras-chave:

Narrativa jornalístiva, Subjetividade, Roberto Saviano

\section{Jornalism and the subjective turn}

\section{Abstract}

The recovery of the 'self' in contemporary journalistic narratives, whose 'effect of truth' is achieved, beside other aspects, through testimony, conceives a mode of relation with events in which the implied subject in the story reveals elements - whether in the distinction of the exotic or in the nearness of the native look that frequently aren't caught up in the objective perception. This article critically recovers the constraining aspects of the objectivity in journalistic narratives and analyses - taking the subjective turn into consideration - especially the work Gomorra, written by Roberto Saviano, his binding of life and circumstance. Evoking the Passolini of the "privateer phase", Saviano engenders, in his complaint against the Camorra, a reflection over the necessity of intervention by the intellectual in the society he lives in, claiming for the bias of truth by crossing, in the narrative, experience, affectivity and information.

Programa de Pós-

Graduação em

Comunicação Social, Interações Midiáticas, da PUC Minas. 


\section{Distâncias}

A recuperação do "eu" em narrativas jornalísticas contemporâneas, embora estas sejam, ainda, manifestações um tanto pontuais para constituírem tendência, concebe um modo de relação com a circunstância em que o sujeito, implicado naquilo que conta, confere ao relato o efeito de verdade principalmente pelo testemunho, desvelando, pela assunção da subjetividade e da afetividade, filigranas do outro, que normalmente escapam à percepção objetiva, e, por vezes, reivindicando, de modo engajado, a intervenção na realidade imediata. Vinculadas à perplexidade daquele que enuncia, essas narrativas são produzidas, em leque amplo, tanto pelo olhar do viajante - um tópos romântico de formação do sujeito - como pelo autóctone, no caso de Gomorra, de Roberto Saviano, relato que nos interessa mais de perto neste artigo. Se, à primeira vista, essas narrativas parecem reproduzir os tipos clássicos dos narradores benjaminianos - o marinheiro e o camponês, distanciados no espaço e no tempo, respectivamente (cf. BENJAMIN, 1994) -, elas são, na verdade, histórias de modelo romântico-realista, que mais denunciam, pela perplexidade, como já dito, a cisão entre alma e ação (ou interioridade e mundo), nos termos de Lukács (2000), do que ensejam possibilidade prática de um "bom conselho".

No caso dos viajantes, como nas narrativas de Lefèvre ( $O$ fotógrafo), Dávila (Diário de Bagdá) ou Pereira ("Viagem a Xangri-Lá"), as marcas impressionísticas, ao permitirem aflorar certa dose de estranhamento, ressaltam o exótico que ainda subsiste em parte do mundo, sendo este aspecto uma importante pedra de toque - não por acaso, as três narrativas citadas referem-se a eventos no Oriente. A matéria de Aldo Pereira sobre o Tibet, publicada na Folha de S. Paulo, em 2009, centra-se, por exemplo, em rituais como o de "sepultamento no ar", em Lhasa - em que cadáveres de "gente comum" (PEREIRA, 2009, p. 6) são esquartejados e levados para consumo dos abutres - e o de circundar certas montanhas e lagos, baseados na crença animista de que os lugares são moradas de divindades. Direcionado ao que emerge como diferença no outro, o relato iniciase, contudo, a partir dos limites do velho corpo do repórter: "Sair do trem para o ar rarefeito, frio e seco da noite outonal de Lhasa e arrastar a bagagem 200, 300 metros até a van que me aguarda fora da estação foi a experiência mais próxima que já tive de uma reta final de uma maratona" (idem, ibidem, p. 4). Adiante, a paisagem do Tibet é descrita como "quase lunar", na sugestão de que aquele lugar é, de fato, um "outro mundo" (idem, ibidem, p. 4), mas uma terra que, convém assinalar, só pode tornar-se estrangeira porque há uma subjetividade ocidental que assim a percebe.

A subjetividade afirmada em Gomorra, obra sobre a Camorra, publicada na Itália em 2006, diferencia-se da desses outros relatos por não ser um recurso de acentuação do exótico no ou-
Se, à primeira vista, essas narrativas

parecem reproduzir

os tipos clássicos dos narradores benjaminianos

- o marinheiro

e o camponês,

distanciados no

espaço e no tempo,

respectivamente

(cf. BENJAMIN,

1994) -, elas

são, na verdade, histórias de

modelo romântico-

realista, que mais denunciam, pela perplexidade, como já dito, a cisão entre alma e ação (ou interioridade e mundo), nos termos de Lukács (2000), do que ensejam possibilidade prática de um "bom conselho" 
tro, mas que permite, em movimento contrário, compreender, na abordagem por dentro daquela sociedade, como o outro (principalmente aquele de outras regiões da Itália) constrói o estigma sobre o indivíduo napolitano (o próprio narrador), que é sempre um chiachiello ou um bbuono, "um perdedor ou um camorrista" (SAVIANO, 2008, p. 144), em uma bifurcação com finais sempre trágicos, a despeito do caminho escolhido. Entrelaçada às linhas da biografia de um jornalista que cresceu em uma sociedade enredada pelos mecanismos de poder da máfia, a reportagem, em sua pulsão de denúncia, declara sua verdade parcial como condição da existência do próprio narrador (como sujeito e linguagem), que não tem outras provas senão aquelas forjadas à própria experiência.

Trata-se mesmo, nesses exemplos, de recuperação do "eu", haja vista os registros de narrativa jornalística em primeira pessoa - mesmo que na forma incipiente da balada e na condição retórica de afirmação da verdade testemunhal - apontados por Davis (1996), no princípio do jornalismo inglês, no século XVI. Em nosso meio cultural, a ascensão da reportagem a partir do final do século XIX deu-se, também, com fortes marcas do sujeito, por exemplo, nas matérias de João do Rio e mesmo em Euclides na Cunha, não o de Os sertões, mas o dos relatos para o Estado de S. Paulo, na cobertura da guerra de Canudos, em que se observa determinada nota lírica. Na matéria enviada de Tanquinhos, Bahia, em 4 de setembro de 1897, o correspondente, que traz consigo "longamente sofreada uma sede indefinível" (CUNHA, 2000, p. 148), que a água pesada do poço que batiza o lugar parece não extinguir, encerra o relato com a imagem de um mapa científico que tenta, em vão, encobrir a solidão do viajante: "Órion fulgura prodigiosamente belo a pequena altura sobre o horizonte, e eu irei afugentar as saudades profundas e evocando noções quase apagadas de astronomia, percorrendo numa romaria olímpica os céus - perdido, entre estrelas..." (idem, ibidem, p. 152).

\section{A presença do mundo pelo apagamento do sujeito: objetividade}

Embora presente no início da reportagem, esse narrador-sujeito rareou-se, no jornalismo moderno, em função da objetividade que se constituiu valor basilar, ético do campo, que passou também a explorar economicamente a noção (feições de neutralidade e independência, em oposição às de partidarismo, alcançam, em tese, público mais abrangente) $)^{1}$. A narrativa jornalística estabeleceu-se no século XX (embora a concepção date do final do Oitocentos) por meio de uma técnica própria, aliando determinado esquema de seleção e disposição de informação ao afastamento do enunciador, cuja objetividade épica, à guisa da historiografia positivista e da voga realista-naturalista oitocentista, faz com

${ }^{1}$ Essa foi a lógica, de acordo com Costa (2009), para o desenvolvimento dos jornais de Adolph Ochs, nos Estados Unidos, no final do Oitocentos. A passagem da gazeta de opiniões para o jornal de notícias fundamentou-se no preceito de que "quanto menos pudesse tomar partido em alguma notícia, quanto mais 'independente' se mostrasse, mais valor teria a notícia, porque interessaria aos vários lados, interessaria todos" (idem, ibidem, p. 156). 
que o evento pareça contar a si mesmo. Sobre esse último aspecto, lembremos que Zola, em ensaio sobre as características do romance de análise e observação de sua época, identificou o declínio da imaginação em favor de um "senso de real", defendendo que a narrativa deveria "colocar em pé criaturas vivas, representando diante de seus leitores a comédia humana com a maior naturalidade possível" (ZOLA, 1995, p. 24). Se um romancista pretendia escrever acerca do mundo do teatro, exemplificou Zola, ele deveria reunir documentos, entrevistar os mais bem informados na matéria, colecionar expressões, passar noites num camarim de uma atriz, enfim, ficar impregnado do máximo possível daquele ambiente para que o romance se estabelecesse por si mesmo. "Sentir a natureza e representá-la como ela é" (idem, ibidem, p. 26), escreveu em defesa da primazia do referente, ignorando como disse Collingwood (1975, p. 293), filósofo da história, acerca do retratista que se dispõe a seguir a teoria estética que impele à cópia - que "é o artista, e não a natureza o responsável por aquilo que surge na tela."

Essas linhas do realismo histórico, angulares também na narrativa jornalística, seriam explicitamente reabilitadas, na condição de "técnicas", pelo new journalism norte-americano na década de 60, que percebia no cenário literário coevo, marcado pela intransitividade do romance modernista, uma oportunidade para se dedicar a um "corpo de material" abandonado pelos literatos: o feixe de relações da sociedade norte-americana, que se mostrava, naquele período, particularmente profuso em transformações na ordem dos costumes e da moral. No entanto, mesmo no new journalism, de forte consciência narrativa - mas não ficcional, pois a narratividade não era compreendida por esses escritores como uma propriedade que implicava o "como se" da ficção, à diferença, por exemplo, do pensamento de Hayden White (1998) acerca da historiografia -, o enunciador buscava anular, no discurso, marcas de sua pessoa passional, o que permitia que o narrador atuasse como um centro de consciências, apresentando as cenas pela perspectiva das personagens, como fez Truman Capote em A sangue frio. Assim, os jornalistas pretendiam o efeito "de estar dentro da cabeça do personagem, experimentando a realidade emocional da cena" (WOLFE, 2005, p.54), evitando o ponto de vista do repórter, considerado muitas vezes "irrelevante para a história e irritante para o leitor" (idem, ibidem, p.54-55).

Barthes (p. 169) observou que a objetividade é "uma carência dos signos do enunciante", o que proporciona o efeito de estreitamento entre o relato e o evento que ele representa. Na narrativa jornalística em terceira pessoa, ainda predominante em notícias e reportagens, a objetividade, como efeito daquilo que parece
Embora presente no início da reportagem, esse narradorsujeito rareouse, no jornalismo moderno, em função da objetividade que se constituiu valor basilar, ético do campo, que passou também a explorar economicamente a noção (feições de neutralidade e independência, em oposição às de partidarismo, alcançam, em

tese, público mais abrangente) 
não ser mediado, é extraída de um movimento semelhante em certos pontos àquele que gera a ilusão referencial na fotografia: o apagamento, pelo maquinal (característico tanto do aparelho fotográfico como, metaforicamente, da técnica redacional - lead, pirâmide invertida, léxico selecionado em função de uma comunicabilidade instantânea e desprovida de ambigüidades, ausência de traços impressionísticos), do gesto autoral e das estruturas imaginárias implicadas na construção daquela realidade. (Podemos dizer que toda notícia possui um redator, mas não propriamente um autor; se as notícias, hoje, em sua maioria, em nossos jornais, são assinadas, isso se deve mais a uma estratégia de responsabilização - ou de conjuração, como no pensamento foucaultiano - que a um ato de recompensa ou reconhecimento de particularidades estilísticas). Como nos diz Cavell (1979, p.23), "photography overcame subjectivity in a way undreamed of by painting, (...) one which does not so much defeat the act of painting as escape it altogether: by automatism, by removing the human agent from the task of reproduction”. É significativo que a teoria contemporânea do jornalismo descreva o contexto de emergência do paradigma informacional, no século XIX, a partir de um movimento intelectual que possui a fotografia como "farol orientador" (TRAQUINA, 2005, p. 52). Retomando o pensamento de Cavell, podemos dizer que, assim como a fotografia, a narrativa jornalística, para manter o senso de presença do mundo, impôs a nossa ausência dele, ou pelo menos nossa existência apenas na condição de observador, já que esse mundo para existir não deve ser conformado, quando narrado, à nossa subjetividade.

Esse apagamento do sujeito no jornalismo (também um elemento de distinção, no campo da comunicação social, em relação às realidades "interessadas" construídas pelas Relações Públicas e pela Publicidade) deu-se, portanto, bem antes do triunfo das estruturas iniciado na década de 1970 e em sentido também diverso, pois não faz da crítica à subjetividade crítica da representação de uma realidade exterior ao discurso, mas, pelo contrário, um método que possibilite que o empírico seja acessado pelo texto.

A crítica que expõe como errônea e ingênua a concepção de contiguidade entre realidade e narrativa - esta, denunciada, como dispositivo a serviço da vontade moderna de ordem (usualmente acompanhada pela vontade de limpeza, que caracterizou os regimes totalitários) -, acirrou-se, mas sem grande influxo sobre a prática jornalística, na segunda metade do século XX, quando os teóricos da descontinuidade, entre eles Hayden White (1998) e Louis Mink (1998), colocaram em relevo os aspectos factícios de todo relato - interessava a eles notadamente aquelas narrativas sob o regime de veracidade. White considerava a narrati- teóricos da descontinuidade, entre eles Hayden White (1998) e Louis Mink (1998), colocaram em relevo os aspectos factícios de todo relato - interessava

a eles notadamente aquelas narrativas sob o regime de veracidade 
va não somente urdidura (emplotment), mas distorção imposta como instrumento de poder e manipulação. Caberia, portanto, ao intelectual, desnudar os artefatos e matrizes constituintes de todo relato, evitando, assim, que as narrativas se degenerassem em mitos, isto é, fossem recebidas sem a consciência de sua ficcionalidade.

$\mathrm{Na}$ perspectiva da guinada linguística, narrativa e objetividade formam um par em que os elementos se apresentam em condição de exclusão. A conhecida frase de Mink (p. 135), "stories are not lived but told", resulta de uma argumentação em que a expressão "História narrativa" é vista como oximoro, já que reivindica, como disciplina, a restauração objetiva do passado em sua complexidade, sendo, entretanto, necessariamente, um produto de construção imaginativa. Nos estudos de jornalismo, Jay Rosen (2000, p. 146) expõe também narrativa e objetividade como valores conflituosos reclamados simultaneamente pelos jornalistas, que "são objectivos e contam-nos histórias", ainda que ser "objectivo não é de todo uma característica de um qualificado contador de histórias", divergência que, de acordo com o autor, pode ser percebida fortemente na dramatização de notícias televisivas, em que os "rituais de objetividade ficam de lado" (idem, ibidem). Após sistematizar uma série de críticas à objetividade jornalística (seu uso como estratégia retórica, técnica de persuasão para proteger o discurso, pois o relato seria ofertado como mediação transparente dos fatos; possibilidade de alienação, pela alegada imparcialidade, do jornalista do debate intelectual; a noção já esgotada de um conhecimento possível sem que nele o conhecedor esteja incorporado), Rosen (idem, ibidem) conclui que a maior perplexidade acerca da objetividade talvez seja encontrar o que irá substituí-la como filosofia pública para o jornalismo, isso em um contexto em que os relatos absolutos deram lugar a uma pluralidade de relatos por vezes conflituosos. Sobre a guerra de Geórgia, em 2008, Zizek (2008. p. 8) assinalou que para “a visão pós-moderna não existe realidade objetiva: nossa realidade consiste em múltiplas histórias que nos contamos sobre nós mesmos", o que constrói um "labirinto" de narrativas "concorrentes".

Embora crivada de críticas, a objetividade permanece como traço da narrativa jornalística, até porque nenhum outro conceito emergiu, ainda, com força suficiente para substituí-la como norte. $\mathrm{Na}$ perspectiva dos veículos, como demonstra o estudo de Costa (2009), a objetividade permanece, mesmo nas considerações ponderadas (como as do manual da Folha de S. Paulo ou de Abe Rosenthal, que reconhecem sua impossibilidade), um ideal, apresentado como alvo ou meta do jornalismo, sendo a discussão acerca de sua angularidade no campo relegada ao âmbito acadêmico.
Embora crivada de críticas, a objetividade permanece como traço da narrativa jornalística, até porque nenhum outro conceito emergiu, ainda, com força suficiente para substituíla como norte 
Neste cenário, vêm à tona, como dissemos, a princípio na condição de arestas, uma série de relatos jornalísticos em primeira pessoa, em que a perspectiva do sujeito não apenas molda a matéria narrada, mas a própria experiência do narrador torna-se parte do fato a ser comunicado. Podemos apreender essas manifestações como relatos resultantes, no jornalismo, da guinada subjetiva, que, principalmente a partir da década de 1970, deu a voz, por meio do testemunho, àqueles até então excluídos dos discursos majoritários.

Os relatos em primeira pessoa - ou em discurso indireto livre, que permite a perspectiva em primeira pessoa - legitimaram-se, em uma de suas faces, como expõe Sarlo (2007), pelo testemunho da experiência vivida no horror das grandes guerras (o Shoah é o exemplo mais contundente) ou dos regimes totalitários, ou seja, em casos-limites, que colocam em "primeiro plano argumentos morais apoiados no respeito ao sujeito que suportou os fatos sobre os quais fala" (SARLO, 2007, p. 37). Os relatos tornaram-se, desde o final do século passado, uma forma de cura, de libertação dos direitos oprimidos da primeira pessoa, em que a experiência comunicada, de lastro biográfico, acabaria por livrar o sujeito da alienação. A retórica testemunhal, de modelo realista-romântico, proporciona seus efeitos de realidade de modo semelhante à voga oitocentista, pela ênfase no detalhe e na notação insignificante, que reforçam o "tom de verdade íntima" (idem, ibidem, p.52) e são aliados à centralidade do "eu" e à noção de juventude obstruída - a dor, entre tantas outras, da juventude confiscada de que fala Primo Levi, em A trégua, após libertação do Lager. Esses são, segundo Sarlo, discursos blindados, pois portadores de uma verdade que é eticamente insuportável questionar, não se prestando à análise, mas servindo como matéria-prima para narração dos eventos e mesmo como peças, em tribunais, para julgamentos que visam possibilitar a instauração dos regimes democráticos. Todavia, como assinala Sarlo, os relatos em primeira pessoa são discursos, e, como tais, devem também ser analisados.

\section{Testemunho e reportagem}

Gomorra, obra em que o jornalismo entrecruza-se ao testemunho, reúne 11 relatos acerca dos mecanismos de atuação da máfia napolitana, a Camorra (como é conhecida, principalmente, pela imprensa e pelo judiciário), mas nomeada, no livro, de "o sistema", pelo seu enredamento na sociedade local e nas economias italiana e internacional. No relato, o olhar autóctone de Roberto Saviano faz dele um narrador que não se restringe à observação da experiência alheia - como propôs determinada teoria acerca do narrador pósmoderno em analogia ao narrador-repórter ${ }^{2}$-, mas que se corporifica na junção entre a afetividade de sua biografia, suas relações

${ }^{2}$ Referimo-nos, aqui, ao conhecido artigo de Silviano Santiago, "O narrador pósmoderno", publicado em Nas malhas da letra (São Paulo, Companhia das Letras, 1989) 
sociais imediatas no cotidiano napolitano e a "escuta" de característica jornalística (matérias da imprensa, transcrições de conversas telefônicas, atas processuais, entre outras fontes). Esse último caráter documental do relato traduz em dados e estatísticas o que é concomitantemente narrado no livro, de forma mais contundente, pelas trajetórias humanas, em que nunca "se vê nada bom no final" (SAVIANO, 2008, p. 144), aliando as dimensões da informação e da vida, uma das funções da reportagem como gênero. Na narrativa sobre o alfaiate Pasquale, a atitude do personagem que, "como que tragado por areia movediça" (idem, ibidem, p. 49), abandona a profissão após ver, pela televisão, um terno branco, cortado por ele, ser usado por Angelina Jolie na noite do Oscar, é apreendida como ato particular de desespero e análise, pois explicita a disparidade entre os milhões de dólares movimentados pela economia da moda, de que a máfia faz parte, e os 600 euros pagos por mês aos trabalhadores das pequenas fábricas de roupas da região. Havia, ali, naquela reação (microscópica, em proporção à grandeza da engrenagem), testemunhada pelo narrador, uma análise argumentada ou, como Saviano compara, quando da descrição do choro de Luisa, mulher de Pasquale, "um capítulo de $O$ capital, de Marx" ou "um parágrafo de A riqueza das nações, de Adam Smith" (idem, ibidem, p. 50).

"Nasci na terra da Camorra, no lugar com o maior número de assassinatos da Europa, no território onda a violência está ligada aos negócios, onde nada tem valor se não gera poder. Onde tudo tem o sabor de uma batalha final" (idem, ibidem, p. 348), escreve Saviano, cuja condição de napolitano é, em seu país, um estigma daí sua hesitação em revelar, em conversa com estranhos, durante viagem de trem, onde nasceu: "Uma cidade tão falada, que basta pronunciar-lhe o nome para ninguém dizer mais nada"(idem, ibidem, p. 193). Posicionar-se contra os clãs - famílias mafiosas, cerca de 80 na região - é, para Saviano, algo "visceral", que, à diferença de um dever cívico, está, organicamente, entranhado à própria existência, permitindo-a. $\mathrm{O}$ narrador reconhece nisso uma espécie de perversão, à guisa de um "mecanismo brechtiano" (idem, ibidem, p. 248) que o faz enxergar, por exemplo, na vida ordinária, não as edificações (casas, prédios, shopping centers etc.), mas a engrenagem do crime organizado que atua na construção civil. "Como alguém que, observando Vermeer, se detivesse mais a pensar em quem misturou as cores, quem esticou a tela no esquadro, colocou as pérolas nos brincos, do que a contemplar o retrato", compara (p. 248). Na escrita, a voz do narrador apresenta-se implicada à subjetividade do autor, vínculo que - a despeito das teorias literárias que percebem o eu autobiográfico como prosopopeia - ressoa nas circunstâncias de publicação e recepção da própria obra, pois Saviano é, hoje, por causa de Gomorra, escritor jurado de morte, vivendo sob escolta do estado italiano. 
Evidentemente, não se trata de reduzir toda obra à interioridade de seu autor, pois se, muitas vezes, a narrativa centra-se na primeira pessoa, ela também objetiva e perfaz, com força maior, de acordo com o modelo realista, seu movimento rumo à ação, ao mundo circundante, denunciando esquemas econômicos diversos (os já citados, que envolvem grifes italianas de moda e a construção civil, o do lixo contaminado, despejado na região, entre outros); o fascínio que o crime exerce sobre parte da juventude napolitana, sob influência do imaginário hollywoodiano; a intrincada trama de duas faces - terror e assistencialismo - pela qual a máfia envolve a sociedade; normas de conduta e estratégias do aparato militar, que, pela precisão como são descritas, revelam a abordagem por dentro daquela realidade. A crueza dessa épica foi, inclusive, levada às telas no filme homônimo de Matteo Garrone, que, em sua narrativa fragmentária e muitas vezes silenciosa, acaba por colocar em relevo, sem que isso seja necessariamente uma imperfeição, justamente a ausência da voz que alinhava, no livro, as histórias, dando a elas determinada tonalidade pela demarcação do lugar de onde se enuncia. Essa subjetividade, em suma, afastada no cinema, manifesta-se, claramente, no texto de Saviano, em "ilhas" ensaísticas, e, mesmo em passagens onde ela parece se apagar, em função da urgência da denúncia, subsiste como lastro testemunhal, conferindo à narrativa não somente o efeito da verdade íntima, mas a gravidade da repulsa que move o sujeito em direção ao relato.

Pensemos nas frases do pai de Saviano, citadas no livro, interpretação da vida acossada pela Camorra: "Há quem comanda as palavras e quem comanda as coisas. Você deve discernir quem comanda as coisas e fingir acreditar em quem comanda as palavras. Mas sempre deve ter a verdade dentro de si. Comanda realmente quem comanda as coisas" (SAVIANO, 2008, p. 199). Contudo, em oposição aos ensinamentos do pai, entre eles o de que um homem é aquele que possui um diploma e uma pistola, Saviano fia-se nas possibilidades da palavra, evocando Pier Paolo Pasolini, em fase corsária, marcada pelas intervenções ideológicas na imprensa, sobretudo no Corriere della Sera, na primeira metade da década de 1970. Nesses escritos, Pasolini investia contra a sociedade de consumo italiana, que homogeneizara a juventude, afetando de modo fascista a consciência e intimidade mesmo daqueles que antes permaneciam, como resistência de uma antiga maneira de ser, à margem da burguesia. Esse novo regime, marcadamente consumista e de poder liberal e hedonista, submetia os jovens, segundo Pasolini, à própria infelicidade, sem que nada pudesse "fazê-los vir a tomar clara consciência dela." (LAHUD, 1993, p. 110). Nesse empenho contra o novo regime, como avaliou Lahud (idem, ibidem, p. 105-106), “nem mais um resquício de humor
Saviano fia-se nas possibilidades da palavra, evocando Pier Paolo Pasolini, em fase corsária, marcada pelas intervenções ideológicas na imprensa, sobretudo no Corriere della Sera, na primeira metade da década de 1970 
pontilhado de ironia que muitas vezes aflorava nas intervenções anteriores, mas o tom permanentemente grave e amargurado do mais absoluto desespero".

Em Gomorra, não somente o tom de Saviano parece ser o mesmo como é possível observar que seu espírito corsário, no percurso da obra, investe também contra o caráter tentacular do consumo, ao constatar a sujeição do mundo dos homens ao mundo das mercadorias. A Itália consumista, em que as mercadorias e o modo de vida ligado a elas aliciam os jovens pobres do sul - onde o estado não chega -, move o crime. No capítulo inicial, "O porto", o golfo napolitano é descrito, de modo bastante semelhante a uma sátira seiscentista de Gregório de Matos acerca da Bahia ${ }^{3}$ violada, "como um ânus de mar que se alarga com muita dor dos esfíncteres" (SAVIANO, 2008, p. 16), para permitir a entrada dos cargueiros abarrotados de produtos, principalmente chineses; a zona rural de Nápoles e Caserta é, no capítulo final, a "terra dos fogos", o destino ilegal de grande parte do lixo europeu produzido pelo consumo.

Saviano (ibidem, p. 246) narra, no livro, a viagem que fez ao túmulo de Pasolini em Casarsa, lugar para refletir sobre a os "mecanismos de poder" e sobre a possibilidade de se "dar nomes aos bois" e confrontar os criminosos "somente com o barro da palavra escrita". Deseja, assim, fazer sua mozione di sfiducia em diálogo aberto com Pasolini, mais especificamente com o conhecido artigo Cos'è questo golpe? Io so, publicado no Corriere della Sera, em 14 de novembro de 1974. Nesse texto, Pasolini escreveu que o verdadeiro intelectual não deve ser comprometido com o poder, pois competia a ele, ainda que não tivesse provas ou indícios, dizer todos os nomes dos responsáveis acerca da série de "golpes" que aconteceram na Itália após o ano de 1968, em cruzada anticomunista. "Il coraggio intelectualle della verità e la pratica politica sono due cose inconciliabili in Italia" (PASOLINI, 2009, s.p.), clamou. A exemplo de Pasolini, Saviano entoa o seu "Eu sei":

Eu sei. As provas não estão escondidas em nenhum pen-drive enterrado num buraco debaixo da terra. Não tenho vídeos comprometedores em garagens escondidas em locais inacessíveis na montanha. Não possuo documentos xerocados dos serviços secretos. As provas não podem ser confrontadas porque são parciais, filmadas pelo olhar, contadas com palavras e temperadas com emoções forjadas a ferro e fogo. Eu vejo, deduzo, olho, falo e, assim, testemunho: palavra feia que ainda pode valer quando revela "É mentira", no ouvido de quem ouve as coisas. De quem ouve a cantilena das rimas balbuciadas pelos mecanismos de poder. A verdade é parcial e, no fundo, se fosse redutível a uma fórmula objetiva, seria química. Eu sei e tenho provas. E, então, conto essas verdades. (SAVIANO, 2008, p. 248)

${ }^{3}$ Ver o soneto "À cidade da Bahia", mais especificamente os versos da segunda estrofe: "A ti trocou-te a máquina mercante/ que em tua larga barra tem entrado/ a mim foi-me trocando, e tem trocado,/ Tanto negócio e tanto negociante" (MATOS, 1999, p. 40) 
As provas "filmadas pelo olhar, contadas com palavras e temperadas com emoções forjadas a ferro e fogo" mostram-se intimamente vinculadas ao autor, cuja atuação, desde o primeiro capítulo, na própria engrenagem - seja como estivador ou pedreiro, derrubando paredes para o armazenamento de produtos - faz dele um "infiltrado" na Camorra sem, contudo, a perspectiva estrangeira que geralmente caracteriza esses sujeitos clandestinos, de vigília secreta. Saviano reivindica, em sua reportagem, a parcialidade da verdade - pois, "no fundo, se [ela] fosse redutível a uma fórmula objetiva, seria química" -, o comprometimento do intelectual que, fora dos círculos de poder, mas visceralmente ligado à circunstância sobre a qual escreve, deve tomar posição em face daquilo que se apresenta como visivelmente corrompido, ainda que as provas objetivas não sejam acessíveis. Nota-se, contudo, que a marcação desse "eu", forjado na experiência de uma circunstância-limite, não se confunde com o vozerio em primeira pessoa de muitos (não todos, evidentemente) relatos dos blogs contemporâneos ou testemunhos literários, em que os sujeitos, na exposição de sua cotidianidade, tornaram-se não mais que mercadorias à venda na sociedade midiatizada. Se, como alerta Rosen, uma das críticas contemporâneas à objetividade reside justamente em uma colateralidade da noção que pode implicar, pela isenção e imparcialidade, em um não comprometimento do jornalista com sua comunidade, a subjetividade de Gomorra, como condição explícita de enunciação que projeta sua experiência e visão informada de determinada realidade aponta, pelo testemunho, um caminho para o relato jornalístico neste início de século.

\section{Referências}

BARTHES, Roland. O rumor da língua. Trad. Mário Laranjeira. 2a. ed. São Paulo: Martins Fontes, 2004.

BENJAMIN, Walter. O narrador. Considerações sobre a obra de Nikolai Leskov. In: Magia e técnica, arte e política: ensaios sobre literatura e história da cultura. Trad. Sérgio Paulo Rouanet. São Paulo: Brasiliense, 1994. p. 197-221.

CAVELL, Stanley. The world viewed. Cambridge, Massachusetts; London: Harvard University Press, 1979.

COLLINGWOOD, R. G. A imaginação histórica. In: A idéia de história. Trad. Alberto Freire. Editorial Presença: Portugal, 1975.

COSTA, Caio Túlio. Ética, jornalismo e nova mídia - uma moral provisória. Rio de Janeiro: Jorge Zahar editor, 2009.

CUNHA, Euclides da. Diário de uma expedição. São Paulo: Companhia das Letras, 2000.

\footnotetext{
Estudos em Jornalismo e Mídia - Ano VI - n. 2 pp. 33 - 44 jul./dez. 2009
} 
DÁVILA, Sérgio. Diário de Bagdá: a guerra do Iraque segundo os bombardeados. São Paulo: DBA Artes Gráficas, 2003.

DAVIS, Lennard J. Factual fictions - the origins of the English novel. New York: Columbia University Press, 1996.

GUIBERT, Emmanuel; LEFÈVRE, Didier; LEMERCIER. O fotógrafo. Trad. Dorothée de Bruchard. São Paulo: Conrad Editora do Brasil, 2006. (2 volumes)

LAHUD, Michel. A vida clara - linguagem e realidade segundo Pasolini. São Paulo: Companhia das Letras, 1993.

LUKÁCS, Georg. A teoria do romance. Trad. José Marques Mariani de Macedo. São Paulo: Duas Cidades; Ed. 34, 2000.

MATOS, Gregório de. Poemas escolhidos. São Paulo: Cultrix, 1999.

MINK, Louis. History and fiction as modes of comprehension In: FAY, Brian, POMPER, Philip e VANN Richard T. (Eds). History and theory contemporary readings. London: Blackwell Publishers, 1998. p. 153-171. PASOLINI, Pier Paolo. Cos'è questo golpe? Io so. In: www.corriere.it/speciali/pasolini/ioso.html. Acessado em 30 de julho de 2009.

PEREIRA, Aldo. Viagem a Xangri-Lá. Folha de S. Paulo. São Paulo, 8 de março de 2009. Mais! p. 4-6.

ROSEN, Jay. Para além da objetividade. Revista de comunicação e linguagem. Trad. Victor Flores. Lisboa: Relógio D’Água Editores, março de 2000. p. $139-150$.

SARLO, Beatriz. Tempo passado - cultura da memória e guinada subjetiva. Trad. Rosa Freire D’Aguiar. São Paulo: Companhia das Letras; Belo Horizonte: Ed. UFMG, 2007.

SAVIANO, Roberto. Gomorra. Trad. Elaine Niccolai. Rio de Janeiro: Bertrand Brasil, 2008.

TRAQUINA, Nelson. Teorias do jornalismo. 2a. ed. Florianópolis: Insular, 2005.

WHITE, Hayden. The historical text as literary artifact. In: FAY, Brian, POMPER, Philip e VANN Richard T. (Eds). History and theory - contemporary readings. London: Blackwell Publishers, 1998. p. 15-33.

WOLFE, Tom. Radical chique e o novo jornalismo. Trad. José Rubens Siqueira. São Paulo: Companhia das Letras, 2005.

ZIZEK, Slavoj. Um mundo desregrado. Folha de S. Paulo. Mais! São Paulo, 24 de agosto de 2008, p. 8

ZOLA, Émile. Do romance: Stendhal, Flaubert e os Goncourt. Trad. Plínio Augusto Coelho. São Paulo: Editora Imaginário: Edusp, 1995.

Recebido em 1 de setembro de 2009 Aceito em 29 de setembro de 2009 